\title{
The parallelogram law in the works of d'Alembert and Kant
}

\author{
Carmen MARTÍNEZ ADAME
}

Received: 4.4 .2011

Final Version: 6.4.2012

BIBLID [0495-4548 (2012) 27: 75; pp. 365-388]

ABSTRACT: We compare two approaches given to the parallelogram law as a fundamental notion in eighteenth century mechanics. The authors we study are Kant and d'Alembert and we use the context created by Newton's Principia as our point of departure.

Keywords: Parallelogram law; composition of motion; phoronomy.

RESUMEN: En este artículo comparamos dos caminos seguidos en el tratamiento de la ley del paralelogramo como noción fundamental en la mecánica del siglo XVIII. Los autores que estudiamos son Kant y d'Alembert y utilizamos el contexto creado por los Principia de Newton como nuestro punto de partida.

Palabras clave: Ley del paralelogramo; composición de movimiento; foronomía.

\section{Introduction}

The history of the parallelogram law, as it is known today, is long and complex; during the XVII Century the use of forces was mainly limited to statics and the laws of impact. However, after Newton, mechanics was to link in an intrinsic manner forces and movement. This tendency was especially obvious during the Enlightenment and it is for this reason that we wish to concentrate in this article on the work of d'Alembert and Kant as two key representatives of the Siècle des Lumières and Aufklärung respectively (d'Alembert and Diderot 1751-1765), for instance, defines mechanics, which is divided into statics and dynamics, as the science that is a part of mixed mathematics, that considers motion and motive forces, their nature, their laws and their effects in machines. (Kant 1786), Metaphysical Foundations of Natural Science, ${ }^{1}$ divides the science of nature into phoronomy, dynamics, mechanics and phenomenology and states that: "natural science is throughout either a pure or an applied doctrine of motion."(Kant 1910-1983, Vol. IV p. 477).

D'Alembert and Kant were contemporaries and yet their work on the subject at hand differs widely which is another reason why we have chosen to compare the two. D'Alembert was born in 1717 and Kant in 1724, a few years after mathematics had encountered many important changes at the hands of Descartes, Fermat, Newton and Leibniz.

\footnotetext{
1 Translations into English will be taken from (Kant 1891).
} 
D'Alembert read Newton's Principia for the first time in 1739. It was an edition published in Geneva prepared by Reverends Le Seur and Jaquiet ${ }^{2}$ and it is well known that d'Alembert studied this text with great care, in fact there are copies of a manuscript dating from this period, Remarques sur quelques endroits des principes de Newton, that has been attributed to d'Alembert.

It is also well known that Kant was greatly influenced by Newton as well. Kant entered university in 1740 where he took courses in logic, ethics, metaphysics, natural law, and mathematics. Martin Knutzen was Kant's advisor and introduced him to Newton's Principia and Optics, and probably led him to think about natural philosophy. It is also documented in (Warda 1922) that Kant had a copy of both the Principia and Optics in his library.

This common influence in d'Alembert and Kant makes it very intersting to compare their different approaches to science in general and in particular, in this case, to the parallelogram law.

Another common influence came from Euler. Although it is undocumented when d'Alembert first read Euler's Mechanica which was published in 1736, it is known that it was around 1743 when Euler first learned of d'Alembert (via his correspondence wiht Daniel Bernoulli) and very soon afterwards they began to correspond regularly on topics of mathematics. What is documented is the fact that Kant had a copy of the Mechanica in his library and in fact an intresting episode regarding Knutzen and Kant and involving Euler began in 1738 .

It was in 1738 that Knutzen became known as an astronomer outside of Königsberg. He had predicted that a comet that had been observed in 1698 would reappear in 1744 . This prediction was apparently based on calculations that depended on Newton's theory of comets, according to which all of them circle the sun. In 1744, a comet did appear, and Knutzen rose to fame. However, soon doubts arose regarding his success. Euler showed both in letters to Knutzen and in an article that appeared in the very same year that Knutzen's prediction had not come true. Euler argued that the comet of 1744 was not the same as the comet of 1698; he stated that the course of the comet was of such a nature that at least four to five hundred years were needed before it could be seen again.

Although Knutzen and some of his students dismissed Euler's criticism, Kant followed the arguments about the comets with great interest. He became very interested in the subject matter and his earliest works deal with such matters. These developments must also have led to Kant's disenchantment with his teachers. It is highly likely that he realized Knutzen's shortcomings as a scientist through Euler's criticisms. In any case, it is very interesting to note that one of the people to whom Kant sent his first work, Gedanken von der wahren Schätzung der lebendigen Kräfte (Thoughts on the True Estimation of

${ }^{2}$ This edition of the Principia was published in four volumes that appeared from 1739 to 1744. It was published in latin and was republished many times throughout the 18th Century.

Theoria 75 (2012): 365-388 
Living Forces) was Euler himself.

The influence that Newton and Euler had on d'Alembert and Kant surely supersedes the parallelogram law, but given that what we intend to study in this article is precisely this, we believe it is important to show how this law is presented in the works of both Newton and Euler.

In Newton's works, and mainly in the Principia the science of nature is ruled by the well known three laws of motion. It is important to note that although these laws deal with forces and forces in fact constitute the core of Newton's work, forces are an a priori concept for Newton and in his treatise he only deals with them in a mathematical manner without taking into account their physical causes.

The first corollary that appears after the three laws shows how forces are to be composed:

A body acted on by [two] forces acting jointly describes the diagonal of a parallelogram in the same time in which it would describe the sides if the forces were acting separately (Newton 1729 , p. 20).

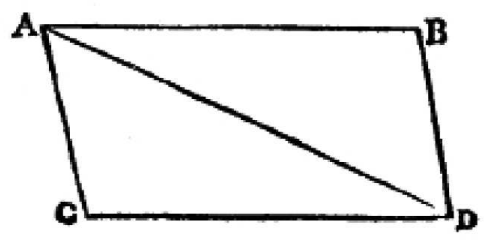

Figure 1: Composition of motion in the Principia.

Newton's proof (which is well known and which we will not reproduce here) shows that the validity of this result could be obtained, according to Newton, from the concept of force itself; he uses the first and second laws and makes implicit use of what is usually known as the postulate of the independence of forces when he supposes that even though forces act on the same body they do so without interfering with each other. It is also interesting to note that Newton presents this corollary as a result that can be obtained through purely dynamical considerations as many of his predecessors had previously established the validity of the result within statics. This is noteworthy as what seems to be at stake is the impossibility of having a notion or concept of force or science that does not comply with the parallelogram law.

It is also important to note that Cohen (Newton 1999, p. 118) interprets this corollary as presenting "the parallelogram law for impulsive forces, that is, for the velocities that such forces produce", in fact, Cohen argues that the first corollary helps to show that impulse is what the word "force" really means in Newton's second law. We will return to this point later on when we present d'Alembert's first proof of the parallelogram law as the contrast of a dynamics, 
and in particular a parallelogram law, based on velocities with one based on forces is central to this paper.

Of great importance is not only Newton's Principia but also Euler's Mechanica sive motus scientia analytice exposita which was published in 1736 in two volumes. It is a work of monumental importance; however we shall not discuss it here as it lays outside the intended scope of this article, we only wish to present Euler's treatment of the parallelogram law. It is important to note from the beginning that the composition law, as it appears in Euler's text is given a very different role from the role that Newton had given it.

The first chapter of the Mechanica deals with motion in general and it is in the second chapter that the effects of forces acting on free points is studied. It is in this chapter that forces are first defined as an action on a free body that either leads to the motion of the body at rest, or changes the motion of that body and it is also in this chapter that Euler introduces the result that interests us here.

Theorem 1. When a point is acted on by many forces, the same motion comes about from these, as if the point is acted on by a single force equivalent to all of these forces (Euler 1736, Section 107).

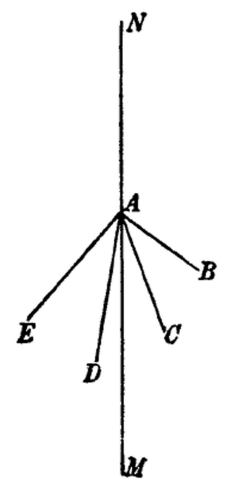

Figure 2: Composition of motion in the Mechanica.

We include the proof of this result as it is perhaps less well known: Let the point $\mathrm{A}$ be acted on by the forces $\mathrm{AB}, \mathrm{AC}, \mathrm{AD}$, and $\mathrm{AE}$, to which the force $\mathrm{AM}$ is equivalent. The equal and opposite position to this, $\mathrm{AN}$, is taken, and as it is known from statics, it will cancel the action of the forces $\mathrm{AB}, \mathrm{AC}, \mathrm{AD}$, and $\mathrm{AE}$. Therefore only the force $\mathrm{AN}$ is impressed on the point $\mathrm{A}$ and the motion is along $\mathrm{AN}$, the magnitude of the forces $\mathrm{AB}, \mathrm{AC}, \mathrm{AD}$, and $\mathrm{AE}$ acting together impress on the point $\mathrm{A}$ the force along the line $\mathrm{AM}$ in the central direction. Truly the force AM alone, since it is equal to the force AN, is of such a size that it moves the point $\mathrm{A}$ along $\mathrm{AM}$, to the same extent as the force $\mathrm{AN}$ moves the point towards AN. Whereby the force AM alone impresses on the point $\mathrm{A}$ 
a motion along $\mathrm{AM}$, as much as the forces $\mathrm{AB}, \mathrm{AC}, \mathrm{AD}, \mathrm{AE}$ acting together along the same direction AM. In each case therefore, the effect is the same.

Two corollaries follow in which Euler states that if a point is acted on by many forces, then it can be considered to be acted on by a single force, which is equivalent to all the other forces; and in turn that in place of a single force acting on a point, there can be considered to be many forces acting, to which the first is equivalent.

It is immediately clear that there is a crucial difference between the results of Newton and Euler. Newton not only aims at showing that two forces acting on a point can be taken as one but is also keen on showing how the resulting force can be obatined. This last part is absent in Euler's result. There is no mention of the parallelogram law merely an assumption (based on statics) that forces can always be composed but it doesn't seem to matter how. The key result, according to Euler, is thus that the composition (or decomposition) is always possible and he is happy to leave it there.

It is thus very interesting to question if the underlying problem is not the computation of the resulting force but merely the knowledge that the resulting force always exists. These remarks are important in light of the proofs we will analyze in what follows.

\section{D'Alembert's work}

In 1743 d'Alembert published his Traité de Dynamique, which consists of a preface and two parts. We will concentrate on the first of these as well as on the preface as it is here that d'Alembert presents the law of composition of motion and a brief philosophy of mechanics as well as the guidelines he will follow throughout his treatise.

It is also in the preface that d'Alembert gives a short definition of the science he is to develop, that is dynamics. However, this definition is widened by d'Alembert himself in the Encyclopédie and we will take it from there as we do not believe this alters the spirit with which the treatise was written.

Definition 1 (Dynamics (Enc.)). The science of powers or causes of motion, that is, of forces that set bodies in motion [...] Mr. Leibnitz was the first who used this term to mean the most transcendent part of mechanics that deals with the motion of bodies as caused by motive forces. [The word dynamics] has been widely used for many years by Geometers to mean in particular the science of motion of bodies that act upon one another (d'Alembert 1755).

Since dynamics refers then to the science of forces one could think that it is not a convenient word for the title of the treatise as mechanics is viewed by d'Alembert as a science of effects and not causes; nevertheless, the author's intentions are clarified within the treatise.

...as the word dynamics is widely used today amongst [scientists] to mean the science of motion of bodies that act upon one another in any given manner; I thought 
I should keep it to announce to the Geometers even with the title of this Treatise that my principal goal is to perfect and augment this part of Mechanics (d'Alembert 1743, p. xxiij).

In order to carry out this goal of widening and improving this part of mechanics, d'Alembert appeals to the concept of certitude in mathematics in the first paragraph of his treatise; it is clear that the only possibility of achieving such a goal is via the mathematization of this science.

Certainty in Mathematics is an advantage that this science owes principally to the simplicity of its object. However, it was to be accepted that [...] not all parts of Mathematics have an equally simple object [...] Many among them, which stand supported on physical principles, that is, on truths that come from experience or on simple hypotheses, only have a certainty that comes from experience or even supposition. There are only, to speak exactly, those that deal with the calculation of magnitudes and general properties of size, that is Algebra, Geometry and Mechanics, that can be viewed as being marked with the stamp of evidence. [...] To treat with the best method possible any part of mathematics it is necessary not only to introduce and apply, as much as possible, knowledge supported by more abstract sciences, and hence by simpler ones, but also to imagine the object of this science int he most abstract and simple way possible (d'Alembert 1743, p. i-iii).

With Newtonian physics as a backdrop it is not difficult to understand d'Alembert's goal and furthermore it could even seem evident, necessary and trivial; however knowing which concepts to include in this mathematization and which ones to drop is d'Alembert's achievement. In fact, he goes on to say that

From this two advantages will emerge: the Principles receive all possible clarity; they are reduced $[. .$.$] to the smallest possible number (d'Alembert 1743, p. iii).$

Here we can find an outline of the method that d'Alembert is to follow in his treatise, this method is clearly guided to trying to obtain the clearest possible principles, that are in their number as few as possible, and to expanding their application as much as possible. With this method d'Alembert expects to attain his primary goal which is the expansion of the principles of this science via their reduction in number.

The method, as described by d'Alembert consists of two parts. The first is the application of more abstract and simple sciences (as geometry and algebra) and the second is an analysis which should be as abstract and simple as possible of the science in question. That is, the former establishes that the science needs to be mathematized and the latter tells us how to carry out this mathematization.

D'Alembert notes that the parts of mathematics that are based upon physical principles, that is, on truths based in turn on experience or simple hypotheses, do not include algebra, geometry and mechanics which can be conceived as sciences which are marked by the stamp of evidence as stated in the quotations above. However, so that these sciences can indeed be treated in this 
way, the objects which they study must be fully understood so that any hint of imprecision can be erased from their principles.

D'Alembert remarks that it is precisely mechanics that has been neglected in this respect and says that "la most of these principles [are] either obscure by themselves or enounced and proved in an obscure manner."(d'Alembert 1743 , p. iv). From this perspective it is easy to understand that the Traité de Dynamique is not a treatise about forces, indeed this is one of the main characteristics of d'Alembert's work, he believes the concept of force to be obscure. The object which is to be the focus of his work is in fact described in the preface: "Motion and its general properties are the first and main object of Mechanics" (d'Alembert 1743, p. v). This point of view marks an important change in the conception of dynamics as d'Alembert's predecessors (such as Newton and the Bernoullis) had developed this science precisely around the concept of force. This is also important if we compare d'Alembert's work with the work of this successors as this trend seems to prevail.

D'alembert's goal within dynamics is very clear:

One can reduce all the Principles of Mechanics to three, the force of inertia, composed motion and equilibrium. At least I hope that with this Treatise I can show that this science can be reduced to these three Principles (d'Alembert 1743, p. 3).

In d'Alembert's work the existence of movement will be presupposed (it will be conceived as the transportation of a mobile body from one place in space to another) and the task of studying its nature is left to the philosophers. It is in this manner that d'Alembert apparently sets aside all questions of causality from his treatise though this does not mean that this is a topic that lacks interest for d'Alembert. In the article on Causes in the Encyclopedie, d'Alembert defines a mechanical or physical cause in the following manner:

Definition 2 (Cause (Enc.)). (in Mechanics 85 in Physics) All that produces change in the state of a body, that is, that sets it in motion or stops it, or alters its motion. ${ }^{3}$

Furthermore, in (d'Alembert 1743, p. x) d'Alembert states that there are two types of causes, ones that occur from the mutual action between bodies due to their impenetrability (that is, impulse and its derived causes) and others that include the action under which bodies fall and other actions at a distance. The first of these are causes that present themselves simultaneously with their effect, like impact phenomena, and thus the impenetrability of matter is one of the principle causes. ${ }^{4}$ Given d'Alembert's search for clear and concise principles

\footnotetext{
${ }^{3}$ See(d'Alembert 1751) This article is of great interest not only for the reasons we mention here but also because it is clear that while writing it d'Alembert had in mind the vis viva controversy. This controversy has been studied by many authors and there exists an ample bibliography, we refer the reader in particular to (Hankins 1965) or (Papineau 1977).

${ }^{4}$ We can understand this term as primary causes.
} 
it is probable that he would have preferred this to be the only primary cause but it is clear that this is not so (d'Alembert 1743, p. xi). In the other type of phenomena the cause does not manifest itself and hence all that can be known is its effect, that is, we are dealing with the second class of causes in which no impulse is manifested and it is not clear whether these actions can someday be reduced to the action of some class of impulse.

The distinction between known and unknown mechanical causes is linked, from d'Alembert's perspective to the issue of necessary and contingent truths, especially when related to the laws of nature. Indeed, the laws of impact are necessary as they are derived from the principle of impenetrability; but the law under which bodies fall is contingent as it can only be discovered experimentally.

The laws of motion, and of composition of motion, are hence necessary and therefore structuring (d'Alembert 1743) around this principle, as one of the three that support this science seems to go well with this point of view. ${ }^{5} \mathrm{Nev}$ ertheless, the idea of not deriving effects from their causes seems to oppose the distinction that d'Alembert makes between necessary and contingent truths; this distinction was made due to the fact that some effects -those whose causes are known- can be derived from their causes in a necessary manner. However, d'Alembert argues that the necessity of the laws of motions and impact is not questioned in this manner as mechanical causes only appear to be causes but in reality are effects that result from other effects (d'Alembert 1751). Our interest here, however, is not to study composition of motion as a necessary truth but as a basic principle of mechanics and we will thus not study this issue any further.

In (d'Alembert 1743) d'Alembert states that he will study movement and composition of movement and not forces and composition of forces. However, in later works d'Alembert seems to interchange these terms rather freely when speaking about the mathematical object with which he will operate; namely, the parallelogram law. This clash of terms motivates this article in part, as we have already mentioned, and thus, we think it is convenient, as we did with the term dynamics, to include the definition of force and of movement.

Definition 3 (Force (Enc.)). Force, is a term much employed in Mechanics and one to which persons involved with mechanics attribute different meanings [...] FORCE OF INERTIA, is the property common to all bodies to remain in their state, either at rest or in motion, unless some external cause is introduced to make them alter this state [...] I used the word property rather than that of force since the latter of these words appears to designate a vague metaphysical being which resides in the body for which we have no precise idea, whereas the former denotes nothing more than an effect constantly observed in bodies [...]

\footnotetext{
${ }^{5}$ This point of view was also held by Daniel Bernoulli who in 1726 wrote an article whose goal was precisely to show that the composition of forces had a necessary character; see (Bernoulli 1726).
} 
In general, we denote by power of motive force anything which obliges a body to move (d'Alembert 1757).

Definition 4 (Motion (Traité.)). [A body] is in motion when it passes from one place to another, that is, when it successively and without interruption occupies parts of space that are immediately contiguous to one another (d'Alembert 1743, p. 2).

Definition 5 (Motion (Enc.)). Is the continuous and succesive change of place of a body, that is, the state of a body in which it corresponds succesivley to different places, or by which it is succesively present in different parts of space (d'Alembert 1765).

In (d'Alembert and Diderot 1751-1765) d'Alembert also includes a definition of composition of motion, which we include here and we call the reader's attention to the last phrase in which d'Alembert states that the laws of composition of forces follow the laws of composition of motion. It is perhaps here that the interchange of these terms is explained.

Definition 6 (Composition of Motion (Enc.)). Is the reduction of several motions into one. Composition of motion takes place when a body is pushed or pulled by several powers at the same time. These different powers can act all in the same direction or along different directions [...] the laws of composition of forces follow those of composition of motions, and one also derives the laws of equilibrium of powers (d'Alembert 1753).

Once we have given these definitions we can begin our analysis of composition of motion but we must point out that it is only through this process that motion can become a mathematical object - the mathematical object that constitutes this science- as it is only when one can operate with it that it contributes to the mathematization of dynamics and not merely to an application of mathematics.

\subsection{D'Alembert and the parallelogram law: Composition of Motion, 1743 - 1758}

(d'Alembert 1743) does not speak of composition of forces as we have anticipated but speaks of composition of motion (as will Kant) and provides his readers the way to compose two motions, that is, to operate with them and in this manner clearly shows the concept of motion as both a mathematical object and the central concept of his treatise.

This result is presented as the first theorem of the second chapter whose title is "On Composed Motion":

Theorem 2. If two arbitrary powers act at the same time on a Body or point $A$ to move it, one from $A$ to $B$ uniformly in a certain time, the other from $A$ to $C$ uniformly during the same time, and if one constructsthe parallelogram 
$A B C D$; I say that the body $A$ will move along the diagonal $A D$ uniformly in the same time it would have moved along $A B$ or AC (d'Alembert 1743, p. 22).

As we have mentioned this result also appeared in (Newton 1687), and even though in that case the result clearly has a lower statute than that of Newton's laws it is clear that it is also a fundamental principle in the Newtonian text.

The proof that Newton gives of this result, is shorter than d'Alembert's but both seem to be built on the same type of reasoning, this draws our attention to d'Alembert's later proofs as they change drastically in nature. And in turn, this is highly of interest because Kant's proof seems to return to these previous types of reasoning as if ignoring the mathematization of the science that has occured.

To prove this result in (d'Alembert 1743), d'Alembert considers an unknown line $A g$, see Figure 3, as the line that a body $A$ travels along and states that this line is clearly a straight line and that $A$ will travel along it in a uniform manner. He also states that this line is in the same plane as lines $A B$ and $A C$ as there is no reason for it to be on another. On the other hand, if when the body were to arrive at a point $g$ on the same line, two powers ${ }^{6}$ acted on it and one of them tended to move it along $g c$ parallel to $A C$ with the same speed that it had at $A$ and along $A C$ in the inverse sense, and the other tended to move it along the line go equal and parallel to $A B$ in the inverse sense and in the same time that it would have taken to travel along $A B$, it is clear that the body would remain at rest at the point $g$. This is due to the fact that its speed and direction at the point $g$ would be the same as the ones it would have if it were moved from this point by two equal and parallel powers along $A B$ and $A C$ and thus, equal and inverse to the powers along $g o$ and $g c$.

Once this is established, d'Alembert imagines that the body $A$, that describes the line $A g$ is on a plane $K L M H$ that can glide along $K L$ and $I M$, parallel to $A C$. As this plane glides all points $g$ describe lines $g c$ equal and parallel to $C A$, at the same time that the body $A$ describes the line $C A$ and in the same time $K L$ and $I M$ move taking along with them the plane in a manner parallel to $A B$ but in the opposite sense, with speed equal to the one which the body $A$ would have along $A B$. It is clear that all the points $g$ on the plane would uniformly describe lines $g a$ equal and parallel to the diagonal $A D$ of the parallelogram $B C$. It is also evident that the point $A$, pushed continuously in this state by four powers that are equal and opposite when taken in pairs, must remain at rest in absolute space. It thus follows that when the body has arrived at $g$ on the plane, this point must be at the place it had when it began to move. Finally, d'Alembert concludes that this cannot happen unless the line $A g$ lies upon the diagonal $A D$ and thus if $g c=A C$ and $g o=A B$ it will be

${ }^{6}$ In the original french text the word that d'Alembert uses is puissances and not forces, however it is worthwhile to note that in the Encyclopédie, puissance is defined as follows: said of a force that while being applied to a machine, tends to produce motion, whether it is produced or not.

Theoria 75 (2012): 365-388 


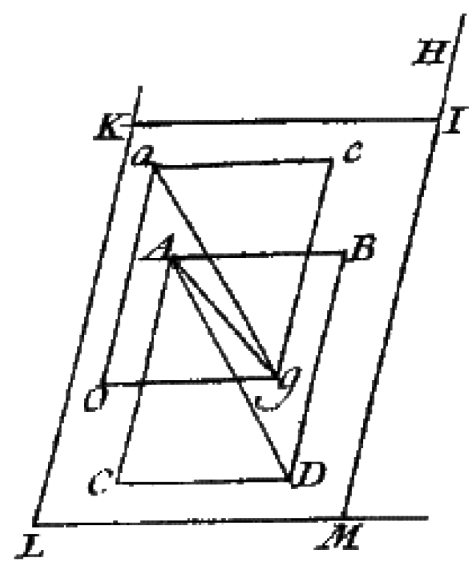

Figure 3: Composition of motion in the Traité de Dynamique.

seen that the point $g$ must lay upon the point $D$ as $g a=A D$ and that the point must coincide with $A$.

It is important to note that d'Alembert includes a note after this theorem in which he explains why he has proven this known result again. He argues that in his proof it is not necessary to use the hypothesis that the powers along $A B$ and $A C$ act during the whole time the body moves. The hypothesis that he holds is that both $A B$ and $A C$ act during a first instant and then, when the movement of the body begins along $A D$ they cease to exist. In this manner the result can now be used under both hypotheses according to d'Alembert. The difference between proving this theorem for impulsive forces or for continually acting forces is non-trivial, especially given the Newtonian framework in which mechanics evolved. Cohen argues that Newton's method of advancing from impulsive to continually acting forces appears after the parallelogram law in the Principia (in Proposition 1 of Book 1). It falls outside the scope of this paper to analyse this method in detail, however what is of considerable importance is noting the difference between the two hypotheses and the fact that it is possible to argue that Newton's use of his second law for continually acting forces follows from the impulsive version that has been stated as an axiom.

Now, if we were to rewrite d'Alembert's theorem in modern language we would have to do so in the following manner: If two instantaneous velocities act on a body, the body will move with a velocity equal to the sum of the two individual velocities. We believe that it is especially worthwhile doing this in light of the first corollary that d'Alembert derives from the law of composition of motion.

Corollary 1. If a body moves or tends to move along a line $A C$ with any given velocity and one takes a point $B$ anywhere on the line $A C$, produced or not, the velocity $A C$ can be considered as composed from the velocity $A B$ and the 
velocity $B C$. For $A C$ can be regarded as the diagonal of a parallelogram whose sides are $A B$ and $B C$ (d'Alembert 1743, p. 25).

D'Alembert notes that this proposition cannot be proven without supposing as an 'incontestable axiom' the fact that the effect of two joint causes is equal to the sum of their effects taken individually, or that two causes act jointly in the same manner that they would act individually. This principle is, according to d'Alembert, neither simple nor evident and he has therefore not used it in this treatise as his objective is to reduce Mechanics to the least number of possible principles and to obtain these principles solely from the idea of motion (that is, from the space that has been traveled and the time that has elapsed) (d'Alembert 1743, pp. 25-26).

This axiom also leads us to the following problem: it assumes that two causes can always act jointly. Hence, instead of asking about the joint effect in relation to the individual effects we need to ask why it is possible to speak of the joint effect at all. In other words, we ask about the existence of a law that allows us to compose any two forces as it is not evident that such a law exists unless it is posited as an axiom. Hence we believe that this has to be the case and furthermore that it operates in accordance to the commutative and associative laws. Thus, in order to talk about a composition law that follows the principle proven in Theorem 1 it is necessary to suppose that two forces, or powers, or motions can always be composed and that this composition is commutative and associative.

This postulate, about the existence of a law that allows us to compose any two forces, does not disappear or become explicit as the different proofs of the parallelogram law evolve in d'Alembert, it is a law that is found in each proof as a tacit postulate.

The second edition of the Traité de Dynamique appears in 1758 and as d'Alembert himself states in its Avertissement the text has grown considerably. However the spirit of the treatise remains unchanged as does the section dedicated to the composition of motion that we have studied and we will thus omit it from our studies here.

D'Alembert gives at least three other proofs of the composition law in 1761, 1769 and 1773 respectively. The proofs differ greatly from this first proof as we shall see in the next section before introducing Kant's proof.

\subsection{Composition of Forces, 1761}

The fifth memoir of the first volume of (d'Alembert 1761) is Démonstration du principe de la composition des forces and has as central reference D. Bernoulli's article of 1726, Examen principiorum mechanicae et demonstrationes geometricae de compositione et resolutione virium, (Bernoulli 1726), in which Bernoulli deals with this issue. D'Alembert states that his goal is to provide the most rigorous and simple proof of the parallelogram law that has been given: 
Mr. Daniel Bernoulli has shown that the problem of the composition of forces can be reduced to proving that if a body is pushed in two directions by equal forces it will describe the diagonal of a rhombus whose sides are the directions of the forces and they be proportional to them [...] The sole merit of the text that one will read here is thus that of proving the composition of forces in the case of a rhombus in a simpler and more rigorous manner (d'Alembert 1761, p. 169).

In this memoir d'Alembert proves the following proposition in a mainly geometrical manner much like his previous proof even though the content itself of the proof presents substantial changes.

Proposition 1. Two equal powers $\alpha \beta$ and $\alpha \chi$, forming any angle between them, will always produce the diagonal $\alpha \delta$ as the resultant (d'Alembert 1761, p. 177). It is worthwhile to note that d'Alembert uses the word power in the statement of the proposition, as well as in the text of the memoir we are citing even though it is the word force that is contained in the title; this shows the freedom with which d'Alembert interchanged both terms.

The proof of this proposition rests on the concept of equilibrium, a concept that is of vital importance in (d'Alembert 1743) and that is treated in such a way that Lagrange a few years later would say that in this work d'Alembert "...reduces all laws of the motion of bodies to those of their equilibrium, and thus reduce Dynamics to Statics." (Lagrange 1778, p. 179).

In fact, the result upon which it is based is the following: "If three equal powers act along the lines $A B, A C$ and $A E$, which form an angle of $120^{\circ}$ among themselves, there will be equilibrium." (d'Alembert 1761, p. 170). And it is from this result, that is considered evident, given that there is no reason for any of the powers to "triumph" over another, that d'Alembert can conclude that the power $A D$, which is the resultant of $A B$ and $A C$, must be equal to $A B$ or $A C$ as it must be equal and opposite to $A E$. D'Alembert thus proves in a remarkably simple manner the result of proposition 1 showing that the resultant must fall upon the diagonal and that it cannot be shorter or longer than it.

However, d'Alembert goes on to provide a different proof of the result in 1769 which is much more analytical. Each new proof provided by d'Alembert distances itself from the proofs of Newton and Euler and heads in the direction of an analytical mechanics as described by Lagrange in 1788. As we have already mentioned this will contrast greatly with the proof offered by Kant in 1786 as we will see in the last section.

\subsection{Composition of Motion (2), 1769}

In 1769 d'Alembert published the Mémoire su les principes de la Mécanique, (d'Alembert 1769), which is divided intro three articles: Sur la composition du mouvement, Sur la force d'inertie and Sur l'équilibre.

This memoir is key, given the Traité de Dynamique as it shows that the principles upon which d'Alembert has erected this science have not changed. 
What is new in this memoir is the functional approach with which the fundamental principles of mechanics are to be treated. We intend to study the article that deals with the composition of motion, however, the opening line of the article dealing with equilibrium is equally important:

Let us supose two equal powers $b q, D F$ applied in opposite directions to any two points $D, b$ of an indefinite lever. I say that it cannot be known how to place on a point $e$, a power equivalent to these two (d'Alembert 1769, p. 283).

The proof of this proposition is brief and is based upon taking other powers equal to the given ones but in the opposite direction. However, what is truly interesting regarding this proposition is the fact that given two powers there does not exist a power that can be considered equivalent to both and hence shows that a difference has to be made in the case of the lever regarding the parallelogram law; it is hence a result that, given our perspective, has an immediate impact upon the notion of force.

Now, in the first article, d'Alembert provides a new proof of the principle of composition of motion. ${ }^{7}$ This new proof has the advantage according to d'Alembert himself that it is contained in a single proposition. This proof distances itself from previous proofs given by d'Alembert as a new functional method is used. D'Alembert presents the given problem in the form of a functional equation whose solution shows that the resultant of two forces cannot but be the diagonal of the parallelogram they form.

D'Alembert considers two forces $A C=a, A B=b$ and their resultant $A F=z$. He then takes a line through $A$ as a symmetry axis and copies the given configuration 'on the other side' of the axis. In this way he arrives at the functional equation given by $a \phi(m)+b \phi(\alpha+m)=z \phi(u+m)$ where $\alpha$ is the angle formed by $A B$ and $A C, u$ is the angle formed by $A F$ and $A C$ and $m$ is the angle formed by $A C$ and the symmetry axis. To solve this equation d'Alembert shows that $\phi(\alpha)=2 \cos \alpha$ given the symmetry of the problem and then goes on to show that $\sin u: \sin (\alpha-u):: b: a$ and hence $z=\frac{b \sin \alpha}{\sin u}$. The article finishes here and it is left to the reader to convince herself that if $z$ satisfies this equality then it is necessarily the diagonal of the parallelogram in the problem.

This memoir has two notes at the end in which d'Alembert announces a new proof:

Since reading this memoir, I have found a new analytic resolution for the Problem of Composition of Motion and I would like to present it on another occasion (d'Alembert 1769, p. 285).

It is very interesting to note that d'Alembert says that the new proof is to be analytic as this makes as wonder if we are not to consider the present one analytic as well. We belive that the answer is no, or at least that it cannot

${ }^{7}$ It is interesting to note that the word motion appears but in the title whereas the text itself deals with forces. 
be considered entirely analytic as the function $\phi$ is not found using only the functional equation but from the use of the figure and the properties that d'Alembert assumes that forces have. He derives that $\phi(\alpha)$ must be 0 if $\alpha=90$ and it is from these data that the author can find the function he is searching for. In other words, the functional equation on its own is not enough to solve the problem.

\subsection{Composition of Forces (2), 1773}

The memoir d'Alembert mentioned in 1769 was published in 1773 as memoir number LI of volume VI of his Opuscules Mathématiques under the title: Recherches sur différens Sujets. Its first article is Nouvelle démonstration du Parallélogramme des Forces This text begins as follows:

In the memoir that I presented on the Principles of Mechanics I announced a new proof of the Parallelogram of Forces. It's this proof that I will give here. It is in reality less simple than the proof that can be read in the cited volume; however, as the use that I make of some functions might be useful to solve other problems of the same type, I believe that the Geometers will not be angered if I share it with them (d'Alembert 1773, p. 360).

D'Alembert limits himself to showing that when any two given forces form a right angle, then the resultant is necessarily the diagonal of the parallelogram they make, and to justify this decision he comments that this restriction is valid and well known since Bernoulli's memoir of 1726. This is interesting to note as d'Alembert has told his audience that the proof he will give will be analytic when in fact the functional method will only be employed in the case of a rectangle and the derivation of the other cases will be made from this together with Bernoulli's proof that is largely geometric in nature. Furthermore, it is using analytic means that d'Alembert shows that the resultant must have the same direction as the diagonal, but to prove that it must have the same size he uses Bernoulli's proof.

To prove the result d'Alembert takes a right angle $B A C$ such that $A B=a$ and $A C=b$ are the two given forces and calls the resultant's direction $A D$.

Let $x=\angle B A D$, it is clear that this angle will be not change if $b$ and $a$ are kept in the same ratio. Let $z$ be this ratio. Now, it follows that the ratio of the sine of $B A D$ to the sine of $D A C$ will be a function $\phi$ of $z$ that can be expressed as $\frac{\sin x}{\sin \left(90^{\circ}-x\right)}$, or $\phi(z)=\tan (z)$.

Now let $n a$ be a force along $A C$ and $n b$ a force along $A V$ with the resultant being $A Q$, and such that $D A Q$ is also right. Furthermore, if $A R$ is the resultant of the total forces that act on $A C$ and $A B$ and the angle is denoted by $D A R=$ $x^{\prime}$, then $\tan \left(x+x^{\prime}\right)=\phi\left(\frac{b+n a}{a-n b}\right)=\phi\left(\frac{z+n}{1-n z}\right)$.

We note that the deduction of the functional equation in this case is much more detailed than was the case in 1769; J. Dhombres argues that d'Alembert wrote the 1769 memoir under pressure and in haste (Dhombres \& Radelet-de 


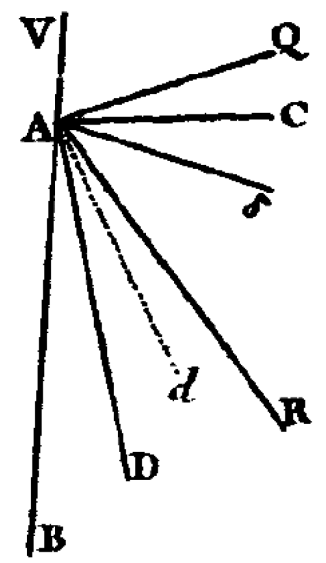

Figure 4: Composition of Forces in (d'Alembert 1773).

Grave 1991) and it is clear that the present text is much clearer and more precise.

Once that the functional equation has been given, d'Alembert transforms it so that it becomes $\tan x^{\prime}=\frac{\phi\left(\frac{z+n}{1-n z}\right)-\phi(z)}{1+\phi(z) \phi\left(\frac{z+n}{1-n z}\right)}$. He also arrives at the fact that $\tan x^{\prime}=\phi(n)$ and hence equating both values of $\tan x^{\prime}$ it follows that $\frac{\phi(z)+\phi(n)}{1-\phi(z) \phi(n)}$ $=\phi\left(\frac{z+n}{1-n z}\right)$. It is from this condition that $\phi$ must be found and to achieve this d'Alembert differentiates both sides of the equation in order to separate the variables and obtains that $\phi^{\prime}(n) \frac{1+n^{2}}{1+\phi(n)^{2}}=\phi^{\prime}(z) \frac{1+z^{2}}{1+\phi(z)^{2}}$, thus $\phi(z)=z$ and $\tan x=z=\frac{b}{a}$ which is the desired result as it implies that the diagonal $A D$ is the direction of the resultant.

In order to solve the differential equation, d'Alembert has added two further assumptions. D'Alembert argues that $\phi(z)$ must be increasing and positive if $x$ is positive given the configuration of the problem, he also adds that $\phi(1)$ must be 1 as $A D$ divides angle $B A C$ into two equal parts when $a$ and $b$ are equal. This condition evidently does not follow from the functional aspect of the memoir and it is taken from the physical nature of the problem. It is also evident that d'Alembert has assumed that $\phi$ is differentiable implying that the functions sought for solutions are functions that meet these conditions and that d'Alembert does not intend to solve the functional equation in terms of more general functions. This is not surprising as any author of that time would have implicitly assumed all functions to be smooth, and furthermore, given d'Alembert's polemics on the vibrating spring, it is clear that he would have been particularly disinclined to consider anything but a function with a continuous derivative.

We believe that it is clear that the proofs we have mentioned in the previous 
subsections are fundamentally analytic and that as such they are notoriously different form the geometric methods used in (d'Alembert 1743, 1758) and (d'Alembert 1761). This difference is particularly rich and interesting given the ideas that have guided the present paper as it allows us to see that the manner in which d'Alembert operates with forces is only via their composition and that it is because of this that this computation has become susceptible of being treated not only with mathematical techniques but within mathematics itself.

We also note that beyond the evolution of d'Alembert's proof techniques, the principle that has remained unchanged is the exclusion of forces as causes from this science and that it is this view point that has allowed the author to further dynamics to this point.

Nevertheless, we believe that even beyond the precise problem at hand -the composition of force - it is the method used by d'Alembert in the last two memoirs that we have cited what is to be the posterity of these texts. D'Alembert structures the functional method used into four stages that seem to allow that the method be used to solve many other problems; the first step is to choose the unknown fucntion, then to establish the functional equation. The last two steps involve the general solution of the equation and the specification of the particular solution. Once established, this method is applicable to solve (within mathematics and not just physics) problems whose nature at first glance was purely mechanical. Thus, this method seems to foreshadow what Lagrange would accomplish a few years later:

Those who value Anlaysis will see with pleasure that Mechanics has become one of its branches and will thank me for thus extending its domain (Lagrange 1778, p. vi).

This contrasts greatly with Kant as we shall see in the following section as his proof of the parallelogram law seems to take us back (in time) to d'Alembert's first proof.

3. Kant and the parallelogram law in the Metaphysical Foundations of Natural Science

Kant's most polished work on the subject of natural science can be found in the Metaphysical Foundations of Natural Science which was published in 1786 between the two editions of the Critique. In the preface to this treatise Kant states that he has followed the "mathematical method" throughout:

I have in this treatise followed the mathematical method, if not with all strictness (for which more time would have been necessary than I had to devote to it), at least imitatively, not in order, by a display of profundity, to procure a better reception for it, but because I believe such a system to be quite capable of it, and that perfection may in time be obtained by a cleverer hand, if stimulated by this sketch, mathematical investigators of nature should find it not unimportant to treat the metaphysical portion, which anyway cannot be got rid of, as a special fundamental 
department of general physics, and to bring it into unison with the mathematical doctrine of motion (Kant 1910-1983, Vol. IV p. 478).

This text seems to point in a similar direction as the preface to d'Alembert's Traité, Kant wishes to treat the Natural Science with the mathematical method and indicates that he has done so. However, given the evolution of the subject at the hands of d'Alembert it is important to question what precise mathematical method Kant has in mind and what he means by it.

Let us first study Kant's work. The Metaphysical Foundations of Natural Science is divided into 4 chapters: Phoronomy, Dynamics, Mechanics and Phenomenology, explained by Kant as follows:

... and thus natural science is throughout either a pure or an applied doctrine of motion. The metaphysical foundations of natural science may thus be brought under four main divisions, of which the first, motion considered as pure quantum, according to its composition, without any quality of the movable, may be termed phoronomy; the second, which regards it as belonging to the quality of the matter, under the name of an original moving force, may be called dynamics; and the third, where matter with this quality is conceived as by its own reciprocal motion in relation, appears under the name of mechanics; and the fourth, where its motion or rest [is conceived], merely in reference to the mode of presentation or modality, in other words as determined as phenomenon of the external sense, is called phenomenology (Kant 1910-1983, Vol. IV p. 477).

In this text we will be concerned mainly with the first chapter of this treatise as it is in this section that the parallelogram law appears. This first chapter is dedicated to Phoronomy which Kant defines "...the pure doctrine of the quantity (mathesis) of motions." (Kant 1910-1983, Vol. IV p. 489) That is, phoronomy does not attribute to matter any other property but that of mobility and it is not concerned with the velocity or direction of motion. For Kant, motion was defined as follows: "Motion of a thing is the change of the external relations of the same to a given space." (Kant 1910-1983, Vol. IV p. 482) Furthermore, an abstraction of the subject is carried out; only the motion of a body with respect to its space is considered. It is worth noting that mobility, for Kant, cannot be conceived a priori and hence is not a pure concept of understanding, that is, it can only find its place in the natural sciences.

\subsection{Composition of motion}

Kant defines the composition of motion as follows:

The composition of motion is the presentation of the motion of a point as bound together in one with two or more motions of the same (point) (Kant 1910-1983, Vol. IV p. 489).

Kant also adds that

Now, as motion is nothing homogeneous, but again motion, Phoronomy is a doctrine of the composition of the motions of the same point according to its direction and 
velocity i.e., the presentation of a single motion as one that comprises within it two or perhaps several motions in one, at the same time, in the same point, so far as they together constitute one, that is, are one with this motion, but not in so far as they produce the latter as causes produce their effects (Kant 1910-1983, Vol. IV p. 489).

We note that phoronomy must determine a priori the construction of motions in general as quantities, and that these motions have to be determined as quantities a priori (in relation to their velocity and direction and with respect to their composition); "To construct the conception of a composite motion means to present a priori in intuition a motion so far as it arises from two or more given [motions] united in one movable." (Kant 1910-1983, Vol. IV p. 486).

This must be established entirely a priori and intuitionally to then become a part of mathematics. Indeed, the rules for the connection of motions through physical causes, that is forces, cannot be shown before the principles of their composition in general are previously laid down mathematically, as a foundation.

We are now led to ask what are the conditions that enable the composition of two motions? This is a question that is not asked in d'Alembert's text and moreover, a question that would be out of place in such a text. On the other hand, Kant presents the answer as the following proposition which is the only proposition in the chapter dedicated to phoronomy.

Proposition. The composition of two motions of one and the same point, can only be conceived by one of them being presented in absolute space, but, instead of the other, a motion of an equal velocity in the contrary direction of the relative space [being presented] as identical with it (Kant 1910-1983, vol. IV p. 490).

In other words, Kant's central argument is that the possibility condition that is being searched for requires two spaces, an absolute and a relative one. Thus the possible relativity of one space, (that is the fact that each motion can be considered as the motion of a body in a space at rest or of a body at rest in a space in motion) is what enables the composition of two motions.

We insist on the fact that when Kant asks what the possibility conditions for the composition of motion are his text contrasts greatly with d'Alembert's, who as we saw tacitly assumes that this is always possible. Another important difference is to be found in the use of the word "composition"; d'Alembert is to understand that two motions will produce a third whereas for Kant the term composition implies that the two given motions are contained in a third and not that they produce it from the changes that one motion produces on the other.

Kant divides the proof of the above proposition about the composition law into three cases: when the two motions lie on the same line and act in the same direction, when they lie on the same line but have opposite directions and finally when the two motions form an angle between them. We shall study the proof of the third case in detail as it is the most general and the one we 
wish to compare to d'Alembert's proofs.

First case: Two motions in the same line with the same direction.

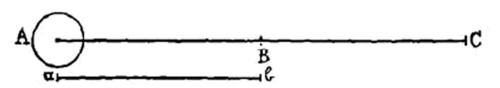

These two motions arrive at the same time in one and the same point. Second case: Two motions in the same line with opposite directions.

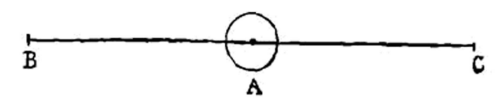

These two motions are united in one and the same point.

Third case: Two motions of the same point are represented as combined according to directions that enclose an angle.

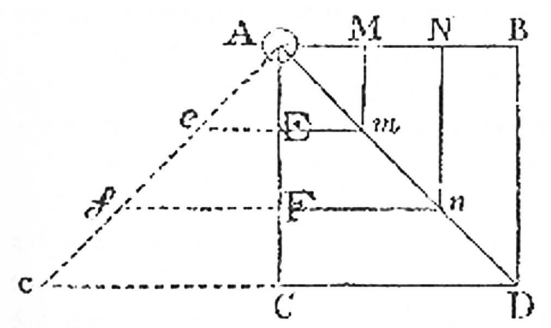

Let the two given motions be $A B$ and $A C$. Kant argues that if these two motions are to occur at the same time in the directions $A B$ and $A C$, and in reality in one and the same space, they would not be able to occur, at the same time, in both these lines $A B$ and $A C$ but only in lines running parallel to these. It would have, therefore, to be assumed, that one of these motions effected a change in the other (namely, the deviation from the given course), although the directions remained the same on either side.

However, this is contrary to the assumption of the proposition, which indicates by the word composition, that both the given motions are contained in a third, and must therefore be identical to it when taken together, and not that a third is produced by one of them upon changing the other.

Now, let the motion $A C$ be taken in absolute space, but instead of the motion $A B$ take the motion of the relative space in the opposite direction. Let the line $A C$ be divided into three equal parts, $A E, E F$ and $F C$. Now, while the body $A$ moves along the line $A E$ in absolute space, the relative space, and therewith the point $E$, covers the space $E e=M A$. While the body moves along the two parts that together $=A F$, the relative space and therewith the point $F$, describes the line $F f=N A$. 
Finally, the body moves along the whole line $A C$ and the relative space, and therewith the point $C$ describes the line $C c=B A$.

All this is the same if the body $A$ had moved along, in these three divisions of time, the lines $E m, F n$ and $C D=A M, A N, A B$, and in the whole time in which it describes $A C$, had had described the line $C D=A B$. The body is therefore at the point $D$ at the last time, and in the whole time, gradually, in all points of the diagonal line $A D$, which represents the direction as well as the velocity of the compound motion. This ends Kant's proof.

It is worthwhile to note that this is the only proposition in this chapter, meaning that phoronomy itself describes the composition of motions and only this. It is equally important to note that this proposition occurs before the introduction of Kant's laws of mechanics in the third chapter of his treatise as this indicates that the composition law in no way depends on them, and this contrasts greatly with Newton's proof for example which depends on Newton's first and second laws. In this sense phoronomy can be seen to be independent from these laws.

This contrasts with d'Alembert's first proof as well, as Kant's proof again only uses one property of matter, namely, movability; whereas d'Alembert uses in his proof a couple of previous results (including his law of inertia). This is perhaps due to the fact that Kant is solely considering motion whereas d'Alembert is considering powers, although as it has already been mentioned these words seem to be almost interchangeable in d'Alembert's proofs. It is also important to note that Kant is dealing with motion that occurs in straight lines whereas d'Alembert has stated this as a law.

We believe that when all these subtle details are added up, one ends up with two proofs that contrast greatly but that have been formulated using the same geometrical language as a backdrop. This certainly changes if we compare Kant's proof to d'Alembert's later proofs.

\section{A few final remarks}

Now, regardless of the differences that we have noted between Kant's proof and the proof that d'Alembert gives in 1743, we note that both are Newtonian in spirit and that hence there are also similarities between the two proofs. Both appeal to the use of motions in absolute (and relative) space and both immediately draw the desired conclusions arguing that things could not be otherwise and hence show the necessary or a priori character of the proposition.

However, there also exist a deeper similarity and a deeper difference between these two proofs. Both Kant and d'Alembert (for possibly different reasons) want to quantify motion. D'Alembert needs to quantify motion in order to mathematize dynamics and Kant needs to do so in order to answer the question about the possibility of composition; however, in doing so Kant turns phoronomy into a geometry (as it deals only with magnitudes) that is different from Euclidean geometry because it requires what we can today call vector 
quantities (quantities with magnitude and direction) and this thus differs from what results from d'Alembert's work.

Regardless of the different motivations that exist for the work of both authors, we note that both proofs are carried out in terms of motions and not forces and in working in this manner both d'Alembert and Kant give this proposition a central place in the edification of the mathematized science of nature in one case or the science of nature dealt with the mathematical method in the other; a science in which the concept of force ceases to be the core.

This is also true if we compare d'Alembert's later proofs with that of Kant. It seems pretty clear, if we study the evolution of d'Alembert's proofs why he produced so many of them. We don't believe he questioned the proof (much less the result) but we do believe that by inlcuding analytic techniques in the proof d'Alembert proved in fact that he had carried out a mathematization of the science at hand. The fact that the parallelogram law could be proved via functional methods shows that d'Alembert had indeed turned it into a mathematical object, a mathematical object treated with state of the art methods in mathematics. In this light it seems surprising that Kant would publish a proof that would regress to older methods.

The fact that Kant's proof is so different from the proof given by d'Alembert in 1773 might indicate that he was unfamiliar with it, and with all the advances made by d'Alembert withtin mathematics in this direction. This is not surprising as these texts are higly technical in nature, however it might also show a different interest at heart. We believe that the analysis we have presented here shows that in dealing with the parallelogram law d'Alembert's work was mostly motivated by the development of mathematical ideas whereas Kant's motivation lay within the development of philosophical ideas.

\section{REFERENCES}

Bernoulli, D. 1726. Examen principiorum mechanicae et demonstrationes geometricae de compositione et resolutione virium. Comentarii Acad. Scientiarum Imperialis Petropolitanae I: $126-142$.

Bernoulli, D. 1987. Die Werke von Daniel Bernoulli Bd. 3. Basel: Birkhauser.

d'Alembert, J. 1743. Traité de Dynamique. Paris: David, Libraire.

d'Alembert, J. and Diderot, D. eds. 1751-1765. Encyclopédie ou Dictionnaire raisonné des sciences, des arts et des métiers. Paris: Briasson, David, Le Breton and Durand.

d'Alembert, J. 1751. Discours préliminaire de l'Encyclopédie Encyclopédie ou Dictionnaire raisonné des sciences, des arts et des métiers, I. Paris: Briasson, David, Le Breton and Durand.

d'Alembert, J. 1751. Analytique Encyclopédie ou Dictionnaire raisonné des sciences, des arts et des métiers, I: 403-404. Paris: Briasson, David, Le Breton and Durand.

d'Alembert, J. 1751. Cause Encyclopédie ou Dictionnaire raisonné des sciences, des arts et des métiers, II: 789-790. Paris: Briasson, David, Le Breton and Durand.

d'Alembert, J. 1753. Composition du Mouvement Encyclopédie ou Dictionnaire raisonné

Theoria 75 (2012): 365-388 
des sciences, des arts et des métiers, III: 769-770. Paris: Briasson, David, Le Breton and Durand.

d'Alembert, J. 1755. Dynamique Encyclopédie ou Dictionnaire raisonné des sciences, des arts et des métiers, V: 174-176. Paris: Briasson, David, Le Breton and Durand.

d'Alembert, J. 1757. Force Encyclopédie ou Dictionnaire raisonné des sciences, des arts et des métiers, VII: 110-120. Paris: Briasson, David, Le Breton and Durand.

d'Alembert, J. 1765. Méchanique Encyclopédie ou Dictionnaire raisonné des sciences, des arts et des métiers, X: 222-226. Paris: Briasson, David, Le Breton and Durand.

d'Alembert, J. 1765. Mouvement Encyclopédie ou Dictionnaire raisonné des sciences, des arts et des métiers, X: 830-840. Paris: Briasson, David, Le Breton and Durand.

d'Alembert, J. 1765. Puissance Encyclopédie ou Dictionnaire raisonné des sciences, des arts et des métiers, XII: 555-556. Paris: Briasson, David, Le Breton and Durand.

d'Alembert, J. 1758. Traité de Dynamique $2^{\text {nd }}$ ed. Paris: David, Libraire.

d'Alembert, J. 1761. Démonstration du principe de la composition des forces. Opuscules Mathématiques 1: 169-179. Paris: David, Libraire.

d'Alembert, J. 1763. publ. 1770. Extrait de différentes lettres de M. d'Alembert à M. de La Grange. Hist. Acad. Roy. Sci. et Belles Lettres Berlin: 235-277.

d'Alembert, J. 1769. Mémoire sure les principes de la mécanique. Mém. Acad. Paris: 278-286. Paris.

d'Alembert, J. 1773. Nouvelle démonstration du parallélogramme des forces. Opuscules Mathématiques 6: 360-370. Paris: Briasson.

Dhombres, J. and Radelet-de Grave, P. 1991. Contingence et nécessité en mécanique: étude de deux textes inédits de Jean d'Alembert. Physis - Riv. Internaz. Storia Sci. 28. 1: $35-114$

Diderot, D. 1910. Obras Filosóficas. Valencia: F. Sempere y Compañía, Eds.

Diderot, D. 1982. Tres Diálogos Filosóficos de Diderot (El sueño de d'Alembert). Mexico: U.N.A.M.

Euler, L. 1736. Mechanica sive motus scientia analytice exposita I \& II. Petersburg: Typographia Academiae Scientiarum.

Hankins, T. 1965. Eighteenth-century attempts to resolve the vis viva controversy. Isis. LVI: 281-97.

Kant, I. 1781. Kritik der reinen Vernunft. Riga: Johann Friedrich Hartknoch.

Kant, I. 1786. Metaphysische Anfangsgründe der Naturwissenschaft. Riga: Johann Friedrich Hartknoch.

Kant, I. 1787. Kritik der reinen Vernunft $2^{\text {nd }}$ ed. Riga: Johann Friedrich Hartknoch.

Kant, I. 1891. Metaphysical Foundations of Natural Science. English translation of Metaphysische Anfangsgründe der Naturwissenschaft by Bax E. B. $2^{\text {nd }}$ Ed. London: George Bell and Sons.

Kant, I. 1910-1983. Gesammelte Schriften. Berlin: Königlich Preukilchen Akademie der Wissenschaften.

Kant, I. 1994. Metaphysical Foundations of Natural Science. English translation of Metaphysische Anfangsgründe der Naturwissenschaft by Friedman M. Cambridge: Cambridge University Press.

Lagrange, J. 1778. Méchanique Analitique. Paris: La Veuve Desaint, Libraire.

Laplace, P. S. 1798. Traité de Mécanique Celeste. Paris: Duprat.

Mach, E. 1942. The Science of Mechanics. Chicago: Open Court.

Newton, I. 1687. Philosophiae naturalis principia mathematica. London: S. Pepys. 
Newton, I. 1704. Opticks. London: Smith and Walford.

Newton, I. 1726. Philosophiae naturalis principia mathematica $3^{\text {rd }}$ ed. London: Innys.

Newton, I. 1729. The Mathematical Principles of Philosophy. Trans. A. Motte. London: Motte.

Newton, I. 1999. The Mathematical Principles of Philosophy. Trans. Cohen I. B. and Whitman A. California: University of California Press.

Papineau, D. 1977. The vis viva controversy: Do meanings matter? Studies in the history and philosophy of science. VIII: 111-137.

Paty, M. 1998. D'Alembert ou la raison physico-mathématique au siècle des Lumières. Paris: Les Belles Lettres.

Warda, A. 1922. Immanuel Kants Bücher. Berlin: Verlag von Martin Breslauer.

Carmen MARTíNEZ ADAME has a PhD in mathematics from King's College, London and currently is associate professor at the Mathematics Department, U.N.A.M., Mexico. Her research topics include the history and philosophy of $18^{t h}$ Century Mechanics and $19^{t h}-20^{t h}$ Century Mathematics with a special interest in the history of mathematical analysis, measure theory and probability.

ADDRESS: Departamento de Matemáticas, Facultad de Ciencias, U.N.A.M., Mexico City, 04510, MEXICO.

E-mail: cmai@matematicas.unam.mx 